\title{
Genome-wide transcriptional response of Trichoderma reesei to lignocellulose using RNA sequencing and comparison with Aspergillus niger
}

\author{
Laure Ries', Steven T Pullan', Stéphane Delmas ${ }^{1,2}$, Sunir Malla ${ }^{3}$, Martin J Blythe ${ }^{3}$ and David B Archer ${ }^{1 *}$
}

\begin{abstract}
Background: A major part of second generation biofuel production is the enzymatic saccharification of lignocellulosic biomass into fermentable sugars. Many fungi produce enzymes that can saccarify lignocellulose and cocktails from several fungi, including well-studied species such as Trichoderma reesei and Aspergillus niger, are available commercially for this process. Such commercially-available enzyme cocktails are not necessarily representative of the array of enzymes used by the fungi themselves when faced with a complex lignocellulosic material. The global induction of genes in response to exposure of $T$. reesei to wheat straw was explored using RNA-seq and compared to published RNA-seq data and model of how A. niger senses and responds to wheat straw.

Results: In T. reesei, levels of transcript that encode known and predicted cell-wall degrading enzymes were very high after $24 \mathrm{~h}$ exposure to straw (approximately 13\% of the total mRNA) but were less than recorded in A. niger (approximately 19\% of the total mRNA). Closer analysis revealed that enzymes from the same glycoside hydrolase families but different carbohydrate esterase and polysaccharide lyase families were up-regulated in both organisms. Accessory proteins which have been hypothesised to possibly have a role in enhancing carbohydrate deconstruction in A. niger were also uncovered in T. reesei and categories of enzymes induced were in general similar to those in $A$. niger. Similarly to A. niger, antisense transcripts are present in T. reesei and their expression is regulated by the growth condition.

Conclusions: T. reesei uses a similar array of enzymes, for the deconstruction of a solid lignocellulosic substrate, to $A$. niger. This suggests a conserved strategy towards lignocellulose degradation in both saprobic fungi. This study provides a basis for further analysis and characterisation of genes shown to be highly induced in the presence of a lignocellulosic substrate. The data will help to elucidate the mechanism of solid substrate recognition and subsequent degradation by T. reesei and provide information which could prove useful for efficient production of second generation biofuels.
\end{abstract}

Keywords: Trichoderma reesei, Aspergillus niger, Glycoside hydrolases, Carbohydrate esterases, Antisense RNA, RNA-sequencing

\section{Background}

The burning of fossil fuels is accompanied by many recognised problems affecting the global economy and environmental health. Replacing fossil fuels with biofuels will help to reduce global $\mathrm{CO}_{2}$ emissions, produce a more favourable greenhouse gas profile, decrease dependence on diminishing oil resources and promote local economies $[1,2]$. The production of biofuels from plant biomass such

\footnotetext{
* Correspondence: david.archer@nottingham.ac.uk

'School of Biology, University of Nottingham, Nottingham NG7 2RD, UK

Full list of author information is available at the end of the article
}

as grasses [3], woods [4,5] and lignocellulosic wastes [6], does not compete with food production and is called second generation (2G) biofuel [7].

In nature, the degradation of lignocellulosic biomass is catalysed by enzymes from various microorganisms such as saprobic fungi and bacteria [7]. Enzymes for biomass deconstruction, and many other industrial applications, are often derived from fungi from the Trichoderma and Aspergillus genera [1]. The overall aim of this study was to investigate the strategy that Trichoderma reesei employs to degrade complex lignocellulosic polysaccharides and compare this to the mechanism used by Aspergillus

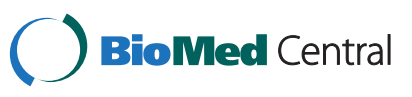


niger in order to provide novel insights which may prompt the development of new approaches for the production of $2 \mathrm{G}$ biofuels.

Trichoderma spp. and Aspergillus spp. have many industrial applications due to their production of very high levels of secreted enzymes $[1,3,8]$. This has led to the development of a wide selection of genetic tools in T. reesei, including random and targeted mutagenesis to create cellulase hyper-producing mutants $[9,10]$, to elucidate regulatory mechanisms of pathways concerning the metabolism of simple sugars $[11,12]$ and to target the $T$. reesei secretion system in order to produce higher protein yields through engineering more efficient and thermostable enzymes [2,9,13-17]. To date, the genome of $T$. reesei has been found to encode a total of 228 polysaccharidedegrading enzymes that represent 61 enzyme families [18]. This is similar to the total number (ca. 280) of carbohydrate-degrading enzymes in A. niger.

This study characterises the transcriptional changes associated with exposure to wheat straw using Next Generation RNA sequencing (RNA-seq) technology, with the aim of gaining an understanding of the steps leading to the deconstruction this complex lignocellulosic substrate. Comparing them to the mechanisms employed by $A$. niger previously described [3], will uncover relevant differences and similarities in lignocellulose degradation between both industrially important organisms. The cost of enzymes presents a major challenge in the cost-effectiveness of biofuel production [19], and the cost of enzymes can be reduced by a combination of factors. Firstly, the yield of enzymes from the fungal source should be maximised and, secondly, the most effective mix of functionalities is required. Other aspects such as the site of production of the enzymes are also important. Ground and autoclaved, but otherwise un-treated, wheat straw was used in this study but a variety of pre-treatments are possible when digesting lignocellulose for the generation of $2 \mathrm{G}$ biofuels. That will inevitably alter the fungal responses but an understanding of the mechanistic basis of those responses requires a base-line study with non-pre-treated material, as described here.

\section{Results and discussion}

The wheat straw -induced transcriptome of T. reesei QM6a

The T. reesei genome is $33.9 \mathrm{Mb}$ in size with 9,126 predicted genes [20]. Transcriptomes were sequenced from replicated independent cultures under 3 different sets of conditions: 1) after growth from conidia for $48 \mathrm{~h}$ in the presence of glucose as sole carbon source, a monosaccharide which represses expression of many genes involved in plant cell wall degradation, 2) $24 \mathrm{~h}$ after transfer of washed mycelia from 1) into media containing ground wheat straw as the sole carbon source to monitor the induction of genes involved in polysaccharide deconstruction and 3) $5 \mathrm{~h}$ after addition of glucose to the straw cultures from 2) to determine genes responsive to carbon catabolite repression. The ball milled wheat straw used in this study contained $37 \%$ cellulose, $32 \%$ hemicelluloses, 22 $\pm 0.1 \%$ lignin and was $25 \%$ crystalline [3]. Statistical tests [21-23] were applied to enable us to identify all genes which were significantly differentially expressed ( $p$-value of $<0.001$ for all three tests) between the three conditions studied (see Additional file 1). RPKM values were calculated for each of the biological replicates as well as for the combined mapping of all replicates at $48 \mathrm{~h}, 24 \mathrm{~h}$ straw and $5 \mathrm{~h}$ glucose (see Additional file 1). The results shown in this study are from the combined mapping scores and only inductions showing a significant score in all statistical tests are discussed.

\section{Expression of CAZy genes in T. reesei and comparison with $A$. niger}

The degradation of plant cell wall carbohydrates is mediated by enzymes of four different classes: the carbohydrate esterases (CEs), the polysaccharide lyases (PLs), the glycoside hydrolases (GHs) and the auxiliary activities (AAs). These enzymes are classed, based on their primary amino acid sequence and related activity, into families in the Carbohydrate Active Enzyme database (CAZy) (www.cazy.org) [24]. Analysis of the T. reesei QM6a genome identified $22 \mathrm{CE}$-encoding genes representing 8 families, 5 PL-encoding genes representing 3 families, 195 GH-encoding genes, representing 49 families and 6 AAencoding genes, representing 1 family [18]. The A. niger ATCC 1015 genome contains 25 CEs representing 9 families, 8 PLs representing 2 families, 239 predicted GHs representing 50 families and 7 AAs representing 1 family [25]. There are differences in the families of CEs, PLs and GHs encoded by the genomes of both fungi $[18,20,25]$. PLs are not as important as GHs and CEs for wheat straw degradation, as PLs mainly target pectin, a structure which is also degraded by enzymes of many GH families, including GH family 28 [26]. The family of AAs encoded by the genomes of $T$. reesei and $A$. niger (AA family 9 ) were formerly known as GH61s but were shown to be copper-dependent oxidases and have a different catalytic mechanism to the GHs [27]. Enzymes of AA family 9 play important accessory roles in enhancing lignocellulose degradation [28].

Carbohydrate esterases which play a role in lignocellulose degradation and which are encoded by $T$. reesei but not by $A$. niger belong to CE family 15 . The genome of $T$. reesei encodes one CE family 15 glucuronoyl esterase [JGI:123940], also known as CIP2, which contains a cellulose binding module (CBM1) and which plays an important role in dissociating lignin from hemicelluloses through targeting the ester bonds between the aromatic alcohols of lignin and the glucuronic acid residues from the xylose 
backbone in hemicelluloses [29]. CE families 8 and 12 are present in $A$. niger but not in $T$. reesei $[18,25]$ and the genome of $A$. niger encodes $3 \mathrm{CE}$ family 8 pectin methylesterases involved in the de-esterification of pectin [30], and two CE family 12 rhamnogalacturonan acetylesterases involved in the deconstruction of plant cell wall pectin [31].

Glycoside hydrolases involved in lignocellulose deconstruction and encoded by $T$. reesei and not $A$. niger belong to $\mathrm{GH}$ families 39, 115 and 45 and assist in the degradation of xylan (GHs 39, 115) and cellulose (GH 45) [18]. In $A$. niger, proteins from $\mathrm{GH}$ families 26 and 51 , which are not encoded by $T$. reesei, are involved in the degradation of hemicellulosic mannan and arabinan residues [26]. Furthermore, the genome of $A$. niger encodes proteins of $\mathrm{GH}$ families 53 and 88, which are involved in the degradation of pectin $[25,26,32]$, inulinases and invertases belonging to $\mathrm{GH}$ family 32 and which degrade polysaccharides containing fructose and sucrose [25].

After $48 \mathrm{~h}$ growth in glucose, CAZy gene mRNA represented $1.14 \%$ of total RNA in T. reesei (c.f. $3 \%$ in $A$. niger, Figure 1), with proteins from GH families 16, 18 and 72 (glucanases, chitinases and glucanosyltransferases) representing approximately half (45\%) of the total CAZy mRNA (Figure 2). Thus in T. reesei, low levels of mRNA from genes encoding enzymes involved in the degradation of complex carbohydrates, including hemicellulose and chitin, are present when the fungus is cultivated in glucose-based medium. In this medium many of these enzymes are likely to be involved in cell wall remodelling during hyphal extension as high growth rates are achieved in the presence of glucose in $T$. reesei [33]. In contrast, in $A$. niger, transcripts from the glucoamylase glaA gene accounted for over $65 \%$ of total CAZy mRNA in glucose medium [3]. Induction of this gene in the presence of glucose and glucosecontaining polysaccharides such as such starch has previously been described [34].

Similarly to $A$. niger, transfer into straw-rich medium for $24 \mathrm{~h}$ caused an increase in CAZy gene mRNA in T. reesei albeit to a lesser extent than in A. niger (13.76\% compared to $19 \%$ of total cellular mRNA, Figure 1). Thirty-three
T. reesei CAZy-encoding genes, representing 17 different $\mathrm{GH}$ families, $3 \mathrm{CE}$ families, 1 AA family and including two accessory enzymes (SWO1 and CIP1), were transcriptionally up-regulated over 20-fold between $48 \mathrm{~h}$ glucose and $24 \mathrm{~h}$ straw samples and reached an expression level above 50 RPKM (Table 1). These results are in agreement with previous microarray data, which showed that genes encoding enzymes of $\mathrm{GH}$ families 3, 5, 11, 28, 30 and of AA family 9 (Table 1) were induced in $T$. reesei mycelia when grown in the presence of wheat straw [18]. Importance of these enzymes in plant cell wall deconstruction is suggested by the presence of well-characterised hydrolase genes such as those coding for BGL1, BGL2 and CEL1B (Table 1). The genome of $T$. reesei encodes 11 predicted $\beta$-glucosidases ( $\mathrm{GH}$ families 1 and 3 ) which were shown to be functionally diverse and differently expressed in the presence of various carbon sources [18]. The extracellular $T$. reesei $\beta$-glucosidase BGL1 has been described as having transglycosylation activity in the presence of insoluble substrates such as crystalline cellulose, and is therefore possibly involved in cellulase gene induction by generating inducer molecules [11]. Moreover, it was also shown that deletion of the intracellular $\beta$-glucosidases BGL2 and CEL1B as well as BGL1 led to a significant delay in $c b h 1$ (cellobiohydrolase CEL7A) induction highlighting an important role for these enzymes in plant cell wall degradation [35]. Proteins from four $\mathrm{GH}$ families $(3,7,11$ and 30$)$ including $\beta$ glucosidases, cellobiohydrolase CEL7A and xylanases; from AA family 9 (copper oxidoreductases) and from CE family 5 (acetyl xylan esterases) represented the majority (approximately 65\%) of mRNA out of the total CAZy mRNA after $24 \mathrm{~h}$ incubation in the presence of straw in $T$. reesei (Figure 2). These proteins are likely to be the main enzymes required for wheat straw degradation. In $T$. reesei and $A$. niger, transcript abundance from genes encoding $\mathrm{GH}$ family proteins $3,5,6,7,11,30,31$ and 67 (glucosidases, cellobiohydrolases, xylanases and glucuronidases) and AA family 9 (copper oxidoreductases) was highest for both organisms (Table 1) indicating that both species use a similar array of GHs for wheat straw

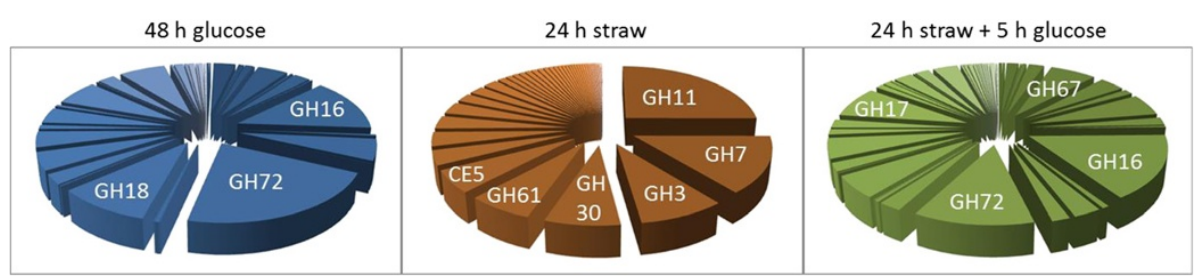

Figure 1 CAZy gene expression. Comparison of the percentage of RNA transcripts corresponding to glycoside hydrolases, carbohydrate esterases and polysaccharide lyases in T. reesei and A. niger when grown for $48 \mathrm{~h}$ in glucose, transferred into straw-based media for $24 \mathrm{~h}$ and with the addition of glucose to straw-incubated cultures for $5 \mathrm{~h}$. Error bars represent standard deviations of the percentage of RNA transcripts corresponding to GHs, CEs and PLs for all replicates. 


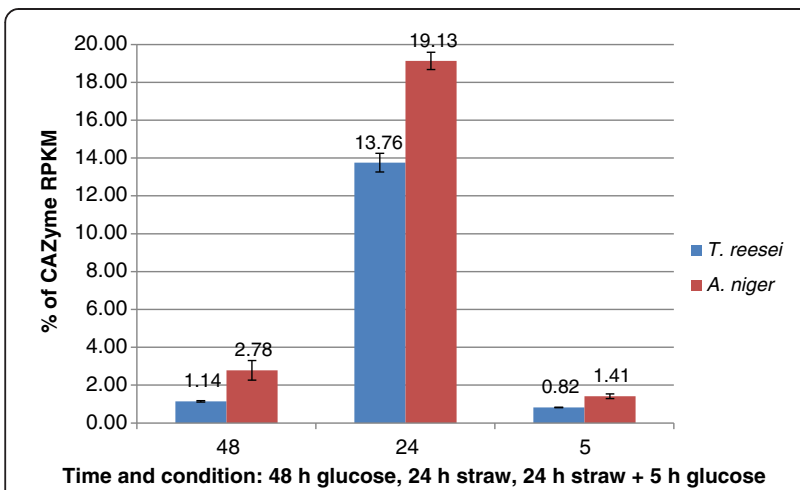

Figure $\mathbf{2}$ CAZy enzyme families. Proportions of total of CAZy gene mRNA from each enzyme family when mycelia were grown in glucose for $48 \mathrm{~h}$, transferred to straw for $24 \mathrm{~h}$ and with the addition of glucose to straw-incubated cultures for $5 \mathrm{~h}$. The enzyme families with the highest RNA percentage for each condition are indicated and listed in decreasing order of expression in the $24 \mathrm{~h}$ straw conditions.

deconstruction. These results were in agreement with results from microarray studies, which showed the induction of genes encoding endoglucanases and mannanases (GH5), cellobiohydrolases (GH6 and 7), $\beta$-glucosidases (GH3), xylanases (GH11 and GH30), enzymes of AA family 9 and acetyl xylan esterases (CE5) in T. reesei mycelia when cultivated in the presence of wheat straw [18]. The same study described the induction of genes encoding enzymes from GH families 16, 18, 27, 55, 95 and 105 in the presence of wheat straw [18]. This is in contrast to the results presented here and is likely to be the cause of the use of different strains (RUTC30 [18] vs. QM6a), differently pre-treated wheat straw (steam explosion [18] vs. ball milled), different conditions (non-inducing, non-repressing [18] vs. repressing) and the use of different sequencing technologies (microarrays [18] vs. RNA-seq). An advantage of RNA-seq, when compared to microarrays, is that it is not limited to detecting transcripts that correspond to known genomic sequences, background signals are low and it does not have an upper limit for quantification [36]. As a consequence, RNA-seq allows for a large dynamic range of expression levels over which transcripts can be detected and has increased sensitivity for genes expressed at either very high or very low levels when compared to microarrays [36]. The patterns of expression of selected GH-encoding genes between $48 \mathrm{~h}$ glucose and $24 \mathrm{~h}$ straw was confirmed by qRT-PCR (see Additional file 2) and were in agreement with the RNA-seq data.

Although both fungi seem to use a similar array of $\mathrm{GHs}$, they up-regulate the expression of different CEencoding genes. Whereas transcripts from CE family 1 were most abundant in A. niger ( $10 \%$ of total CAZy mRNA), transcript levels of genes encoding proteins in
CE family 5 were highest in $T$. reesei ( $\sim 5 \%$ of total CAZy mRNA). This is an agreement with previous microarray studies [18]. The genome of $T$. reesei encodes 3 acetyl xylan esterases and 1 cutinase, all belonging to $C E$ family 5 [18]. The highest expression values were recorded for 2 acetyl xylan esterases [JGI:73632, JGI:54219] one of which contains a CBM1 module [JGI:73632]. Acetyl xylan esterases remove acetyl groups at $\mathrm{O}-2$ and $\mathrm{O}-3$ positions of the xylose chain in arabinoglucuronoxylans [5], a process which has been shown to significantly enhance subsequent hydrolysis of xylans and cellulose [37]. The genome of $A$. niger encodes 3 CE family 1 members: one acetyl xylan esterase, one feruloyl esterase and one undefined esterase [25]. Expression values of the acetyl xylan esterase and the feruloyl esterase were very high in the presence of straw [3]. Feruloyl esterases cleave ferulic acid groups which are esterified to the $5^{\prime}-\mathrm{OH}$ of arabinofuranosyl groups (arabinose residues linked to $O-$ 2 or $\mathrm{O}-3$ of xylose) and which can be covalently linked to lignin or other ferulic acid groups in xylans [5]. It appears that the enzyme mix secreted by $A$. niger aids in loosening the lignin-hemicellulose structure in addition to de-acetylating the xylan backbone in order to allow access of other CAZymes to the underlying hemicellulose and cellulose polysaccharides. Thus the bulk of GH and AA enzymes used to degrade straw are from the same GH and AA families in both organisms, whereas different CE family members are used suggesting that both fungi specialised also in the cleavage of different bonds found within plant cell walls.

Not surprisingly, transcript abundance of PL-encoding genes was very low in both fungi $(\sim 0.012 \%$ of total CAZy mRNA in $T$. reesei and $\sim 0.5 \%$ of total CAZy mRNA in $A$. niger), confirming that PLs do not play an important role in wheat straw degradation (as mentioned above). Similar results were obtained through previous microarray studies [18].

T. reesei also highly induced the transcription of genes encoding proteins other than hydrolases, which have been proposed to be involved in enhancing cellulose degradation (Table 1). One such enzyme is the expansinlike swollenin, swo1 (Table 1), thought to play a role in the loosening of the plant cell wall by disrupting hydrogen bonds between plant polysaccharides, thus increasing cell wall area and access of hydrolytic enzymes (such as cellulases) to the underlying polymers [38]. Another enzyme, CIP1 (Table 1), which contains a CBM belonging to family 1 , is thought to enhance cellulose hydrolysis [9]. Transcript levels of cip1 were also detected in the presence of sophorose and regulation of this gene is the same as for other well characterised cellulases (e.g. $c b h 1)$, indicating a potential role for this protein in cellulose degradation [39]. Our results show that genes encoding both enzymes are highly induced in 
Table 1 Straw-induced CAZy genes

\begin{tabular}{|c|c|c|c|c|c|}
\hline Transcript ID & Annotation [18] & CAZy Family & $48 \mathrm{~h}$ Glucose RPKM & 24 h Straw RPKM & 5 h Glucose RPKM \\
\hline 123818 & Endo- $\beta-1,4-x y l a n a s e$, xyn2 & $\mathrm{GH} 11$ & 3.26 & 3776.93 & 3.72 \\
\hline 123989 & Cellobiohydrolase, cbh1 & $\mathrm{GH} 7$ & 1.57 & 2345.54 & 2.38 \\
\hline 111849 & Endo- $\beta-1,4-x y l a n a s e$, xyn 4 & $\mathrm{GH} 30$ & 1.18 & 1219.13 & 0.99 \\
\hline 121127 & Beta-xylosidase, bx/1 & $\mathrm{GH} 3$ & 0.85 & 1182.53 & 2.15 \\
\hline 72526 & Alpha-glucuronidase glr1 & GH67 & 0.86 & 1024.64 & 0.71 \\
\hline 72567 & Cellobiohydrolase, cbh2 & GH6 & 0.58 & 861.40 & 0.92 \\
\hline 73632 & Acetyl xylan esterase, axel & CE5 & 0.77 & 676.15 & 0.56 \\
\hline 73643 & Copper-dependent monooxygenase, cel61a & AA9 & 0.72 & 668.44 & 1.03 \\
\hline 123992 & Swollenin, contains CBM1, swo 1 & Not determined & 3.94 & 592.13 & 2.08 \\
\hline 74223 & Endo- $\beta-1,4-x y l a n a s e$, xyn 1 & $\mathrm{GH} 11$ & 0.32 & 500.83 & 0.05 \\
\hline 120749 & Beta-glucosidase, bg/2 & $\mathrm{GH} 1$ & 1.53 & 476.91 & 9.38 \\
\hline 120961 & Copper-dependent monooxygenase, cel61b & AA9 & 0.47 & 476.22 & 0.40 \\
\hline 120312 & Endo- $\beta$-1,4-glucanase, egl2 & GH5 & 0.36 & 471.52 & 0.22 \\
\hline 121418 & Acetyl Esterase, aes 1 & CE16 & 0.27 & 342.73 & 0.32 \\
\hline 69944 & Candidate a-xylosidase/a-glucosidase & $\mathrm{GH} 31$ & 0.26 & 327.82 & 0.20 \\
\hline 73638 & Candidate cellulose binding protein, CBM1, cip1 & Not determined & 0.25 & 323.47 & 0.41 \\
\hline 103049 & Candidate endo-polygalacturonase & $\mathrm{GH} 28$ & 0.33 & 227.26 & 0.27 \\
\hline 76210 & Alpha-L-arabinofuranosidase, abf2 & GH62 & 0.36 & 224.30 & 0.04 \\
\hline 54219 & Acetyl xylan esterase & CE5 & 0.04 & 216.93 & 0.16 \\
\hline 49081 & Xyloglucanase, cel74a & $\mathrm{GH} 74$ & 1.22 & 213.92 & 0.60 \\
\hline 122780 & Candidate exo-rhamnogalacturonase, $r g \times 1$ & $\mathrm{GH} 28$ & 0.84 & 130.03 & 2.04 \\
\hline 56996 & Beta-mannanase, man 1 & GH5 & 0.09 & 108.27 & 0.15 \\
\hline 76672 & Beta-glucosidase, bgl1 & $\mathrm{GH} 3$ & 0.04 & 105.71 & 0.22 \\
\hline 62166 & Beta-mannosidase & $\mathrm{GH} 2$ & 1.88 & 98.68 & 4.04 \\
\hline 22197 & Beta-glucosidase, cel1b & $\mathrm{GH} 1$ & 1.11 & 94.50 & 1.42 \\
\hline 123283 & Alpha-L-arabinofuranosidase I, abf1 & GH54 & 0.49 & 91.97 & 0.39 \\
\hline 122081 & Endo- $\beta$-1,4-glucanase, eg/1 & $\mathrm{GH7}$ & 0.03 & 91.03 & 0.14 \\
\hline 123940 & Glucuronoyl esterase, cip2 & CE15 & 0.05 & 87.99 & 0.13 \\
\hline 80240 & Beta-galactosidase, bga1 & GH35 & 0.61 & 87.67 & 0.18 \\
\hline 124016 & Alpha-galactosidase, agl2 & GH36 & 0.76 & 82.70 & 0.59 \\
\hline 74198 & Candidate a-1,2-mannosidase & GH92 & 0.12 & 72.91 & 0.03 \\
\hline 112392 & Candidate endo- $\beta-1,4$-xylanase, xyn5 & $\mathrm{GH} 11$ & 0.04 & 64.84 & 0.10 \\
\hline 110894 & Candidate endo- $\beta$-1,6-galactanase & $\mathrm{GH} 30$ & 0.58 & 57.01 & 0.20 \\
\hline
\end{tabular}

Highly expressed CAZy-encoding genes with an RPKM value greater than 50 at $24 \mathrm{~h}$ straw and an over 20 -fold expression between $48 \mathrm{~h}$ glucose and $24 \mathrm{~h}$ straw.

the presence of straw and that they are regulated similarly to CAZy enzymes-encoding genes, suggesting that these enzymes could be key players in wheat straw degradation. Genes encoding CIP1 and swollenins are absent from the genome of $A$. niger.

Addition of glucose to the straw cultures exerted strong carbon catabolite repression of the CAZyencoding genes, and CAZy transcript abundance decreased to $0.82 \%$ in $T$. reesei $(1.4 \%$ in $A$. niger, Figure 1 ) of the total cellular mRNA, with members from $\mathrm{GH}$ families 16, 17, 67 and 72 (glucosidases, glucuronidase and glucanosyltransferases) (and GH15 in A. niger) being the most expressed CAZy genes under this condition in T. reesei (Figure 2).

\section{Expression of non-CAZy genes in T. reesei and comparison with $A$. niger}

Thirty-two genes in T. reesei which do not encode CAZy enzymes were up-regulated more than 20-fold and reached an RPKM greater than 50 after transfer for 24 hours from glucose to straw-based media (Table 2). In $A$. niger, highly induced genes encoding non-CAZy 
Table 2 Straw-induced non-CAZy genes

\begin{tabular}{|c|c|c|c|c|}
\hline Transcript ID & Annotation & $48 \mathrm{~h}$ Glucose RPKM & 24 h Straw RPKM & 5 h Glucose RPKM \\
\hline \multicolumn{5}{|c|}{ Lipases } \\
\hline 64397 & Ceramidase family protein, associated to cellulase signal transduction & 2.40 & 95.94 & 1.08 \\
\hline \multicolumn{5}{|c|}{ Surface interacting proteins } \\
\hline 119989 & HFB2, class II hydrophobin & 0.79 & 503.22 & 262.84 \\
\hline 74282 & Q174 orthologue, cell wall protein & 0.30 & 272.50 & 12.53 \\
\hline 123967 & HFB3, class II hydrophobin & 0.54 & 182.32 & 33.50 \\
\hline 104277 & Cell wall protein, contains HsbA conserved domain & 0.15 & 87.68 & 0.29 \\
\hline 124295 & Cell wall protein with a CFEM domain & 0.17 & 58.28 & 9.80 \\
\hline \multicolumn{5}{|c|}{ Enzymes of carbon and nitrogen metabolism } \\
\hline 107776 & Xylose reductase XYL1 & 2.79 & 294.24 & 4.42 \\
\hline 123009 & Glutamine synthetase & 7.90 & 214.02 & 176.34 \\
\hline 80340 & Alpha1,6-mannosyltransferase & 0.18 & 117.78 & 3.34 \\
\hline 120784 & Aldose-1-epimerase & 1.43 & 106.24 & 1.96 \\
\hline 81271 & Xylitol dehydrogenase XDH1 & 3.58 & 74.44 & 4.64 \\
\hline 49753 & L-arabinitol 4-dehydrogenase LAD1 & 0.07 & 55.57 & 0.32 \\
\hline \multicolumn{5}{|c|}{ Transporters } \\
\hline 3405 & MFS (major facilitator superfamily) permease & 1.14 & 1658.36 & 2.94 \\
\hline 50894 & MFS permease & 0.37 & 466.75 & 0.60 \\
\hline 104072 & Xylose transporter & 0.27 & 324.06 & 0.30 \\
\hline 69957 & MFS permease & 0.24 & 314.19 & 0.48 \\
\hline 82309 & Predicted MFS transporter & 0.47 & 152.99 & 0.17 \\
\hline 120017 & Oligopeptide transporter & 1.84 & 141.28 & 8.13 \\
\hline 106330 & MFS transporter & 0.52 & 92.17 & 0.65 \\
\hline 50618 & MFS transporter & 0.14 & 88.17 & 0.58 \\
\hline 38812 & Iron transporter & 0.66 & 68.02 & 5.06 \\
\hline 80863 & MFS transporter & 1.80 & 67.87 & 9.25 \\
\hline 46794 & Oligopeptide transporter & 0.17 & 56.32 & 3.48 \\
\hline \multicolumn{5}{|c|}{ Gene regulation } \\
\hline 44747 & SNF2 family helicase & 6.21 & 228.14 & 23.38 \\
\hline 80980 & Peptidyl arginine deiminase & 0.09 & 118.95 & 10.07 \\
\hline 108357 & $\mathrm{C}_{2} \mathrm{H}_{2}$ transcriptional regulator & 0.62 & 108.73 & 0.65 \\
\hline \multicolumn{5}{|c|}{ Oxidation-related } \\
\hline 80659 & Alcohol oxidase AOX1 & 0.95 & 1618.88 & 1.03 \\
\hline 56840 & GFO_IDH_MocA dehydrogenase & 1.93 & 407.87 & 1.56 \\
\hline 76696 & Flavin-containing monooxygenase & 0.67 & 111.38 & 0.49 \\
\hline 123827 & Bifunctional catalase/peroxidase & 4.13 & 105.08 & 6.58 \\
\hline 22771 & Dehydrogenase & 2.01 & 79.27 & 1.02 \\
\hline 123978 & Methanol oxidase & 0.21 & 61.55 & 0.24 \\
\hline
\end{tabular}

Highly expressed non-CAZy-encoding genes with an RPKM value greater than 50 at $24 \mathrm{~h}$ straw and an over 20-fold expression between $48 \mathrm{~h}$ glucose and $24 \mathrm{~h}$ straw.

proteins were divided into 5 broad categories [3]. Interestingly, genes belonging to 4 of these functional categories (lipase, surface interacting proteins, enzymes of the carbon and nitrogen metabolism and transporters) were also highly induced in $T$. reesei suggesting a similar approach for both organisms when responding to the presence of ground wheat straw. Moreover, two more broad functional categories could be defined in $T$. reesei under these criteria: proteins involved in gene regulation and oxidation-related enzymes (Table 2). 


\section{Lipases}

In $T$. reesei, one lipase-encoding gene had a similar transcriptional pattern to many $\mathrm{GH}$ and $\mathrm{CE}$-encoding genes. The gene contains a secretion signal and encodes a protein belonging to the neutral/alkaline non-lysosomal ceramidase family which hydrolyse the sphingolipid ceramide into sphingosine and free fatty acid, bioactive lipids serving as cellular messengers [40]. The alkaline ceramidase described here is thought to be involved in cellulase signal transduction [41]. NCBI BLASTP analysis revealed the protein encoded by this gene [JGI:64397] to be highly similar to a ceramidase [JGI:120161] in A. niger, which was also highly induced in the presence of straw [3]. It is possible that this ceramidase is secreted with, and maybe regulated in a similar manner to the CAZy enzymes and participates in wheat straw deconstruction, although expression of this gene in the presence of other lignocellulosic substrates requires further characterisation. This gene presents an interesting candidate for future studies on enzymes which could be involved in plant cell wall degradation.

\section{Hydrophobic surface interacting proteins}

Five genes encoding two hydrophobins and three cell wall proteins were induced in $T$. reesei when switching from glucose to straw and all genes were repressed when glucose was added to the cultures. These genes have a transcriptional profile similar to many genes of the CAZy group. Hydrophobins can adsorb to hydrophobic surfaces and to interfaces between hydrophobic and hydrophilic phases, thus mediating the interaction of the fungus with its environment [42,43]. In Aspergillus oryzae, the hydrophobin RolA recruits the esterase CutL to the synthetic polyester polybutylene succinate-co-adipate (PBSA) and promotes its degradation [43]. A similar role for the two highly expressed hydrophobins of $T$. reese $i$ could therefore be envisaged, as has been proposed for two A. niger hydrophobin-encoding genes which were also highly induced in the same conditions [3]. The other three highly induced cell wall protein-encoding genes are likely to also have a role in mediating interactions of the fungus with a solid substrate. The QI74 cell wall proteinencoding gene has been shown to be induced in Trichoderma harzianium when replacing glucose medium with chitin, simulating mycoparasitic conditions [44]. NCBI BLASTP analysis of the protein encoded by the gene with transcript ID 104277 (Table 2) revealed the presence of putative conserved domain which is also found in the HsbA (hydrophobic surface binding protein A) superfamily; an enzyme family which differs in structure and mechanism of surface interaction, when compared to hydrophobins [43]. In A. oryzae, HsbA also recruits the cutinase CutL to PBSA to promote its degradation [43]. The third gene [JGI:124295] described here, encodes a cell wall protein with a predicted extracellular CFEM (conserved fungal specific extracellular membranespanning) domain. Some Pth11-like GPCRs (G-protein coupled receptors) have associated CFEM domains and are important for sensing surface cues [45,46]. Pth11-like GPCRs were first described in Magnaporthe grisea, where they play an essential role in plant host invasion and pathogenicity $[45,46]$. The observation of the induction of hydrophobic surface interacting protein-encoding genes in both $T$. reesei and $A$. niger suggests that the recognition of solid surfaces is an important step in the fungal response to the plant cell wall and further experiments are required to confirm this. Nevertheless, genes encoding hydrophobic surface interacting proteins present interesting candidates which potential roles in enhancing lignocellulose degradation.

\section{Transporters}

Eleven genes, encoding seven transporters of the major facilitator superfamily (MFS), one xylose transporter, two oligo-peptide transporters and one iron transporter were highly transcribed in straw and repressed in glucose-rich conditions. The MFS superfamily is a large family of transporters which can be divided into a further 17 families of which families 1, 5 and 7 mediate monosaccharide (hexoses, pentoses) and oligosaccharide transport into the cell by coupling it to proton symport or antiport [47]. The first gene listed in Table 2 [JGI:3405] is possibly involved in hexose and disaccharide transport as NCBI BLASTP analysis of the encoded protein [JGI:3405] revealed $75 \%$ amino acid sequence identity to a hexose transporter from Glomerella graminicola [48] and 74\% identity to a lactose permease from Verticillium dahlia. This transporter may belong to family 1 of MFS transporters which couple sugar uptake to proton symport and which are involved in the uptake of galactose, quinate, lactose, maltose and $\alpha$-glycosides [47]. NCBI BLASTP analysis of the protein [JGI:50894] encoded by the second gene listed in Table 2 [JGI:50894] revealed 76\% sequence identity to a high affinity glucose transporter from Gaeumannomyces graminis and it may belong to family 7 of MFS transporters which couple hexose to proton import and are involved in the uptake of fucose, galactose and glucose [47]. The induction of transporter-encoding genes after $24 \mathrm{~h}$ in the presence of straw indicates that the cellulose and hemicellulose fractions of the wheat straw are being degraded, subsequently releasing simple sugars which are taken up by the fungus.

\section{Carbon metabolism}

As in A. niger [3], genes of the xylose utilisation pathway such as xylose reductase XYL1 (Table 2) and xylitol dehydrogenase XDH1 (Table 2) were up-regulated more than 20-fold (Table 2) when switching from glucose to 
straw. XYL1 also reduces the pentose sugar Larabinose to L-arabinitol which is then further oxidised to L-xylulose by the L-arabinitol dehydrogenase LAD1 (Table 2) [49]. In addition, LAD1 is also involved in the alternative pathway of D-galactose metabolism whereas aldose-1-epimerase (Table 2) catalyses the first step of the Leloir pathway of D-galactose catabolism [50]. This indicates that after $24 \mathrm{~h}, T$. reesei had internalised hemicellulosic sugars such as xylose, arabinose and galactose which had then entered their respective metabolic pathways.

\section{Antisense transcription}

Regulation of gene expression can also occur at the post-transcriptional level through regulatory RNAs. Natural antisense transcripts (NATs) are non-protein coding, fully processed mRNAs, which can partially overlap the protein-coding transcripts and which have many regulatory roles [51]. NATs have been found in several fungi including $A$. niger and $N$. crassa $[3,52]$. To calculate the levels within our $T$. reesei transcriptomes, the number of reads corresponding to the noncoding strand was counted for each gene and AS (antisense) RPKM values were calculated in each condition. Approximately 1.82\%, $1.47 \%$ and $2.79 \%$ of all reads in $T$. reese $i$ were antisense reads when mycelia were grown in $48 \mathrm{~h}$ glucose, $24 \mathrm{~h}$ straw and $24 \mathrm{~h}$ straw +5 h glucose respectively. Thus, AS transcription was detected in $T$. reesei and 630 genes had an AS RPKM $>1$ in at least one condition (see Additional file 3 ). The 630 genes encoded proteins involved in a wide variety of cellular functions. The $\%$ of AS transcripts was similar in $T$. reesei when compared to A. niger [3].

The ratio of antisense:sense expression under glucose $48 \mathrm{~h}$ and straw $24 \mathrm{~h}$ conditions was calculated for these 630 genes in order to find genes with AS transcripts which change between the two conditions. Most of these genes have a low AS/S ratio on $24 \mathrm{~h}$ straw indicating that sense transcripts dominate over AS reads in this condition.

Confirmation of the presence of NATs in $T$. reese $i$ was achieved by strand-specific PCR analysis for a gene [JGI:76852] with NATs (Figure 3). This gene is predicted to encode a secreted $\beta$-glucuronidase, belonging to $\mathrm{GH}$ family 2. Strand-specific RT-PCR confirmed the presence of spliced and non-spliced $S$ and AS transcripts of different sizes (Figure $3 \mathrm{~B}$ and $\mathrm{C}$ ) in all three conditions as was previously reported for a gene containing NATs in $A$. niger [3]. Regulation at the post-transcriptional level presents an interesting area for further research.

\section{Conclusions}

This study explored the mechanisms used by T. reesei to degrade an industrially-relevant substrate (wheat straw) for the generation of biofuels and made comparison with the strategies employed by A. niger [3]. Both fungi encode a mix of predicted GHs, CEs and AAs and some families are species-specific. In the presence of wheat straw, many of the CAZy protein-encoding genes were up-regulated in the two fungi and repressed in both glucose conditions. $T$. reesei and $A$. niger use a set of core enzymes from the same $\mathrm{GH}(3,7,11,30$ and 67) and AA (9) families but from different CE families for wheat straw degradation. The amount of CAZy mRNA (as a proportion of total cellular RNA) in T. reesei after $24 \mathrm{~h}$ incubation in straw was less than that in A. niger (number of CAZy-encoding genes represent $\sim 2.5 \%$ of the coding genome in both organisms). Thirty-two genes encoding non-CAZy enzymes in $T$. reesei had an expression pattern similar to the CAZy-encoding genes. The majority of these genes could be classed into functional categories which were also described in A. niger [3], suggesting a similar approach for both fungi to the degradation of a solid, lignocellulosic substrate. Furthermore, as described in $A$. niger [3], the existence of NATs (a type of regulatory RNA) were also shown to be present in $T$. reesei. This presents an interesting area for future research as regulatory RNAs may be involved in the post-transcriptional regulation of genes encoding enzymes involved in carbohydrate degradation. The use of Next Generation RNA sequencing has allowed us to gain preliminary insights into the global gene expression profile in response to a complex lignocellulosic substrate and to identify genes in $T$. reesei, which encode enzymes which have previously not been associated to lignocellulose deconstruction. Furthermore we have confirmed the presence of a type of regulatory RNAs which have not previously been described in $T$. reesei yet.

\section{Methods}

\section{Strains and growth conditions}

T. reesei QM6a $[53,54]$ was used throughout this project. Conidia were produced from glycerol stocks of $T$. reesei grown on potato dextrose agar medium (PDA: $4.0 \mathrm{~g} / \mathrm{L}$ potato extract, $15.0 \mathrm{~g} / \mathrm{L}$ agar, $20.0 \mathrm{~g} / \mathrm{L}$ ) at $28^{\circ} \mathrm{C}$. Conidia were harvested with $2 \mathrm{ml} 0.01 \%$ (w/v) Tween 80 . Liquid batch cultures were inoculated at a concentration of $10^{5}$ spores/mL.

Strains were cultured in $100 \mathrm{ml}$ Trichoderma Minimal Media [TMM: $15 \mathrm{~g} / \mathrm{L} \mathrm{KH}_{2} \mathrm{PO}_{4}, 5 \mathrm{~g} / \mathrm{L}\left(\mathrm{NH}_{4}\right)_{2} \mathrm{SO}_{4}, 10 \mathrm{~g} / \mathrm{L}$ of the respective carbon source, $0.005 \mathrm{~g} / \mathrm{L} \mathrm{FeSO}_{4} .7 \mathrm{H}_{2} 0$, $0.0016 \mathrm{~g} / \mathrm{L} \quad \mathrm{MnSO}_{4} . \mathrm{H}_{2} \mathrm{O}, \quad 0.0014 \mathrm{~g} / \mathrm{L} \quad \mathrm{Zn} . \mathrm{SO}_{4} \cdot \mathrm{H}_{2} \mathrm{O}$, $0.0037 \mathrm{~g} / \mathrm{L} \mathrm{CoCl}_{12} \cdot 6 \mathrm{H}_{2} 0,0.6 \mathrm{~g} / \mathrm{L} \mathrm{MgSO}_{4}, 0.6 \mathrm{~g} \mathrm{CaCl}_{2}$ ] in $250 \mathrm{~mL}$ Erlenmeyer flasks at $28^{\circ} \mathrm{C}$, shaking at $150 \mathrm{rpm}$. Mycelia were grown for $48 \mathrm{~h}$ in $1 \%(\mathrm{w} / \mathrm{v}) \mathrm{glu}-$ cose, after which they were removed by filtration through Miracloth (Merck), washed with doubledistilled water $\left(\mathrm{ddH}_{2} \mathrm{O}\right)$, and transferred to fresh media 


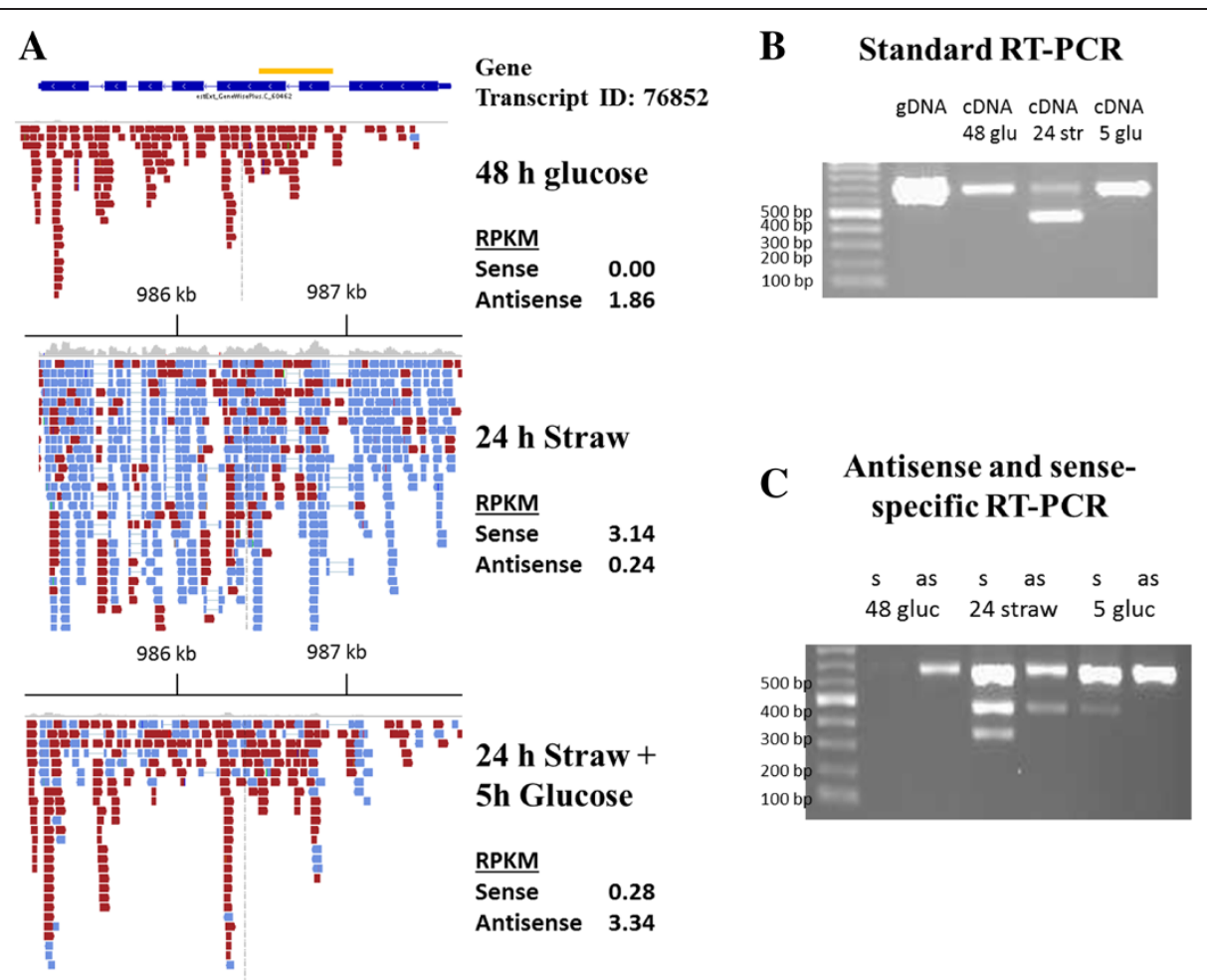

Figure 3 Sense and antisense transcription of gene with ID 76852. (A) IGV (Integrative Genome Viewer) output of the alignment of RNA-seq reads to the genome region corresponding to gene transcript ID 76852 under each condition. Blue reads represent sense RNAs, red reads represent antisense RNAs. (B) RT-PCR using gene specific primers (indicated by a yellow line) on oligo(dT) primed cDNA. The expected band size from spliced, sense transcripts is $476 \mathrm{bp}$ and the size of the non-spliced antisense transcripts is $670 \mathrm{bp}$ and has the same size as products from reactions run on gDNA. (C) Strand-specific RT-PCR using one of the standard PCR primers to synthesise CDNA from one strand only and then the PCR step was performed by using the same primer together with the opposing gene-specific primer. In $24 \mathrm{~h}$ straw and $5 \mathrm{~h}$ glucose both antisense (extend differently over both introns) and sense (differently spliced introns) transcripts are present, explaining the presence of multiple PCR products.

supplemented with the relevant carbon source at $1 \% \mathrm{w} / \mathrm{v}$. Three different sets of conditions were distinguished: 1) growth from conidia for $48 \mathrm{~h}$ in the presence of glucose as the sole carbon source $(48 \mathrm{~h}$ glucose), 2) $24 \mathrm{~h}$ after transfer of washed mycelia from 1) into media containing ground wheat straw as the sole carbon source (24 h straw) and 3) $5 \mathrm{~h}$ after addition of glucose to the straw cultures from 2) (5 h glucose). Transcriptomes were analysed from triplicate cultures of $48 \mathrm{~h}$ glucose and $24 \mathrm{~h}$ straw and from duplicate cultures of $5 \mathrm{~h}$ glucose.

Ball milling, sugar, lignin and crystallinity analysis of the wheat straw used in this study can be found elsewhere [3].

\section{RNA extraction}

Mycelia from each condition were snap-frozen and ground to a fine powder under liquid $\mathrm{N}_{2}$ using a mortar and pestle. $100 \mathrm{mg}$ of mycelial powder was used for RNA extraction, the procedure of which was described elsewhere [3]. Briefly, total RNA was extracted from mycelial powder using TriZol reagent (Invitrogen) according to manufacturer's instructions. Extracted RNA was purified using the Qiagen RNeasy Mini Kit following the manufacturer's instructions of the RNA clean-up protocol with oncolumn DNA digestion.

\section{RT-PCR and qRT-PCR}

The synthesis of CDNA was carried out as described by [3]. PCR reactions were performed using RedTaq DNA Polymerase (Sigma) and $1 \mu \mathrm{L}$ of cDNA in a $20 \mu \mathrm{L}$ reaction. PCR conditions were 30 cycles of denaturation at $94^{\circ} \mathrm{C}$ for $1 \mathrm{~min}$, annealing at $60^{\circ} \mathrm{C}$ for $2 \mathrm{~min}$ and extension at $72^{\circ} \mathrm{C}$ for $3 \mathrm{~min}$. Strand-specific PCRs (ssPCRs; as described in [3]) were carried out at an annealing temperature of $64^{\circ} \mathrm{C}$ using the primer pairs indicated in the Additional file 4.

qRT-PCR reactions were run using the same system as described by [3] and carried out for 40 cycles with denaturation at $95^{\circ} \mathrm{C}$ for $30 \mathrm{~s}$ and annealing at $64^{\circ} \mathrm{C}$ for $30 \mathrm{~s}$ and extension at $60^{\circ} \mathrm{C}$ for $60 \mathrm{~s}$. Briefly, qRT-PCR reactions were run in triplicates per gene in each condition 
in a total reaction volume of $20 \mu \mathrm{L}$ containing $11.0 \mu \mathrm{l}$ Fast SYBR green master mix (Applied Biosystems), $0.11 \mu \mathrm{L} /$ primer (175 $\mathrm{nM}$ final concentration), $2.2 \mu \mathrm{L}$ of cDNA and $8.58 \mu \mathrm{L} \mathrm{ddH}_{2} \mathrm{O}$. Gene expression values were calculated against a standard curve of known genomic DNA concentrations. All primer pair sequences are listed in the Additional file 4.

\section{RNA-seq and subsequent data analysis}

Ribosomal RNA was degraded in $10 \mu \mathrm{g}$ of total RNA using the Ribominus Eukaryotic kit (Invitrogen). SOLiD whole transcriptome libraries were made according to the SOLiD Whole transcriptome kit protocol (Applied Biosystems) and the library concentrations were measured with the Quant-it HS dsDNA assay kit (Invitrogen). Libraries were pooled to equimolar amounts (Invitrogen) and gel purified using 2\% size-select E-gels to 200-300 bp (Invitrogen). Emulsion PCR (0.5 M final concentration of pooled libraries) and bead-based enrichment was done according to the SOLiD 4 Templated bead preparation guide containing library. Sequencing was carried out on a SOLiD $4 \mathrm{ABi}$ sequencer platform according to manufacturer's instructions to generate single fragment $50 \mathrm{bp}$ colour space reads.

Using the BioScope version 1.3 Whole Transcriptome Pipeline (LifeTechnologies), reads from each SOLiD 4 libraries were initially filtered against sequencing library adaptors and other sequencing artefacts. Reads were then mapped independently to the entire unmasked and masked versions of the annotated genome assembly of T. reesei, and to defined gene transcript sequences (JGI $T$. reesei assembly version 2 , annotation filtered models version 2.0). For mapping against the genome assemblies, it was also possible to align reads against a library of exon junctions derived from the exon coordinates detailed in the genome annotation. This allowed reads spanning exon boundaries to be included in alignment results and be recorded in BAM format. Subsequently, the reads corresponding to rRNA encoding gene regions were removed from the BAM records before further downstream analysis. The resulting BAM file of mapped reads from each sample against the unmasked and masked genomes were processed with HTseq-count [3] to generate read counts per gene from uniquely aligned reads. These counts were determined for both the sense strand only and to both strands (unstranded). Summary metrics for these results are shown in Additional file 5.

When comparing the read alignment metrics between the unmasked and masked genome assemblies a negligible difference of less than $1 \%$ is seen for total mapped reads, uniquely mapped reads and for reads mapped within annotated genes. This suggests that the masked regions of the genome do not correspond to transcribed genomic regions. The percentage of reads that were uniquely mapped to the unmasked assembly, as a proportion of total mapped reads, was $63.60 \%$ for all 48 h glucose replicates, $69.64 \%$ for all $24 \mathrm{~h}$ straw replicates and $52.95 \%$ for the $5 \mathrm{~h}$ glucose duplicates (Additional file 5).

For transcript sequence read mapping, less than half the total number of mapped reads compared to the mapping against the annotated genome was observed for all conditions. This can be explained by the difference in reference sequence space used in mapping. Transcript sequences were derived from the annotated exon coordinates within the genome sequence; therefore it would not be possible to map reads corresponding to transcribed regions outside of these defined coordinates. These unmapped reads could be attributed to incomplete annotation of the genome and/or to reads that are not mRNA coding. This is supported by a similar number of uniquely mapped reads to the transcripts within gene coordinates of the genome mapping when compared to the transcripts. The percentage of reads mapped uniquely to transcripts sequences, as a proportion of total transcript mapped reads, was $38.49 \%$, $54.93 \%$ and $33.83 \%$ for the conditions $48 \mathrm{~h}$ glucose, $24 \mathrm{~h}$ straw and $5 \mathrm{~h}$ glucose respectively (Additional file 5 ).

For gene expression analysis the mapped read counts per gene calculated against the unmasked genome. Counts were determined for both sense strand only and to both strands (unstranded), as described previously. Antisense read counts per gene were calculated by subtracting the sense counts from the other. Read counts were then normalized to RPKM (Reads Per Kilobase per Million mapped reads) expression values for each gene [3] and visualised with the Integrative Genome Viewer (IGV 1.5) programme [3].

Differential expression values were determined using DEGseq [23] using sense read counts per gene for each experimental condition. DEGseq implements three independent statistical tests (Fisher's Exact Test [21], Likelihood Ratio Test [22] and an MA-plot-based method with the Random Sampling method [23]).

\section{Availability of supporting data}

The raw and processed RNA-sequencing data sets supporting the results of this article are available in the NCBI's Gene Expression Omnibus [55] repository under GEO accession number GSE44648 [http://www.ncbi. nlm.nih.gov/geo/query/acc.cgi?acc=GSE44648].

\section{Additional files}

Additional file 1: Individual gene sequencing information. Mapped reads and RPKM values for the three biological replicates and the combined values of all three replicates as well as statistical significance scores for all genes at $48 \mathrm{~h}$ glucose, $24 \mathrm{~h}$ straw and $24 \mathrm{~h}$ straw $+5 \mathrm{~h}$ glucose. 
Additional file 2: qRT-PCR of GH-encoding genes. Transcript levels of genes encoding one $\mathrm{GH}$ family 7 protein (CBH1, [JGl:123989]), one GH family 11 protein (XYN2, [JGl:123818]) and two GH family 61 proteins (CEL61A [JGI:73643] and CEL61B [JGI:12961]) in mycelia grown for $48 \mathrm{~h}$ in glucose-based medium and then transferred into media containing straw as the sole carbon source for $24 \mathrm{~h}$. Error bars indicate the standard deviation for three replicates and * indicates significant difference (a pvalue of $<0.0001$ in an equal variance, one-tailed $T$ test) between transcript levels at $48 \mathrm{~h}$ glucose and $24 \mathrm{~h}$ straw.

Additional file 3: Antisense RNA. Antisense and sense RPKM values and ratios for all genes with an antisense RPKM $>1$ in either $48 \mathrm{~h}$ glucose, $24 \mathrm{~h}$ straw and/or $24 \mathrm{~h}$ straw $+5 \mathrm{~h}$ glucose.

Additional file 4: Primer pair details. Sequences, annealing temperatures and predicted gene product sizes.

Additional file 5: Summary metrics of the number of reads. Total number of reads, total number of filtered reads, amount of mapped and uniquely mapped reads to both DNA strands (stranded and unstranded), percentage of total mapped reads and percentage of uniquely mapped reads of total mapped reads corresponding to the $T$. reesei unmasked genome, masked genome and transcript sequences for each sample.

\section{Abbreviations}

AA: Auxiliary Activities; AS: AntiSense; CAZy: Carbohydrate Active enzyme; CBM: Cellulose Binding Module; CE: Carbohydrate Esterase; CFEM: Conserved fungal specific extracellular membrane-spanning; GH: Glycoside Hydrolase; GPCR: G-Protein Coupled Receptor; MFS: Major Facilitator Superfamily; NAT: Natural Antisense Transcript; PL: Polysaccharide Lyase; RPKM: Reads Per Kilobase of exon model per Million mapped reads; S: Sense.

\section{Competing interests}

The authors declare that they have no competing interests.

\section{Authors' contributions}

SD, STP and DBA conceived and designed the experiments. LR and SM carried out the experiments. LR, SD, STP, MJB and DBA analysed the data. MJB contributed the reagents/materials/analysis tools. LR, SD, STP and DBA wrote the paper. All authors read and approved the final manuscript.

\section{Acknowledgements}

This work was supported by grants from the BBSRC CASE studentship, Roal Oy (Finland) and LACE/BSBEC. The authors would also like to thank Christian Kubicek and his team for the annotation of the Trichoderma reesei genome.

\section{Author details}

'School of Biology, University of Nottingham, Nottingham NG7 2RD, UK. ${ }^{2}$ Université Pierre et Marie Curie (UPMC, Université Paris 06), Sorbonne Universités, UMR 7138, Systématique Adapation et Évolution, 75005 Paris, France. ${ }^{3}$ Deep Seq, Centre for Genetics and Genomics, Queen's Medical Centre, University of Nottingham, Nottingham NG7 2UH, UK.

Received: 5 April 2013 Accepted: 6 August 2013

Published: 9 August 2013

\section{References}

1. Banerjee G, Scott-Craig JS, Walton JD: Improving enzymes for biomass conversion: a basic research perspective. Bioen Res 2010, 3:82-92.

2. Fukuda $\mathrm{H}$, Kondo A, Tamalampudi S: Bioenergy: Sustainable fuels from biomass by yeast and fungal whole-cell biocatalysts. Biochem Eng J 2009, 44:2-12.

3. Delmas S, Pullan S, Gaddipati S, Kokolski M, Malla S, Blythe MJ, Ibbett R, Campbell M, Liddell S, Aboobaker A, Tucker GA, Archer DB: Uncovering the genome-wide transcriptional responses of the filamentous fungus Aspergillus niger to lignocellulose using RNA sequencing. PLoS Genet 2012, 8:e1002875.

4. Zhu JY, Pan X, Zalesny RS Jr: Pre-treatment of woody biomass for biofuel production: energy efficiency, technologies and recalcitrance. Appl Microbiol Biotechnol 2010, 87:847-857.

5. Dodd D, Cann IKO: Enzymatic deconstruction of xylan for biofuel production. GCB Bioen 2009, 1:2-17.
6. Dashtban M, Schraft H, Qin W: Fungal bioconversion of lignocellulosic residues; opportunities and perspectives. Int J Biol Sci 2009, 5:578-595.

7. Alvira P, Tomas-Pejo E, Ballesteros M, Negro MJ: Pretreatment technologies for an efficient bioethanol production process based on enzymatic hydrolysis: a review. Bioresource Technol 2010, 101:4851-4861.

8. Elkins JG, Raman B, Keller M: Engineered microbial systems for enhanced conversion of lignocellulosic biomass. Curr Opin Biotech 2010, 21:657-662.

9. Schuster A, Schmoll M: Biology and biotechnology of Trichoderma. Appl Microbiol Biot 2010, 87:787-799.

10. Ike M, Park J-Y, Tabuse M, Tokuyasu K: Cellulase production on glucosebased media by the UV-irradiated mutants of Trichoderma reesei. Appl Microbiol Biot 2010, 87:2059-2066.

11. Kubicek CP, Mikus M, Schuster A, Schmoll M, Seiboth B: Metabolic engineering strategies for the improvement of cellulase production by Hypocrea jecorina. Biotechnol Biofuels 2009, 2:6834-6848.

12. Portnoy T, Margeot A, Seidl-Seiboth V, Le Crom S, Chaabane FB, Linke R, Seiboth B, Kubicek CP: Differential regulation of the cellulase transcription factors XYR1, ACE2 and ACE1 in Trichoderma reesei strains producing high and low levels of cellulase. Eukaryot Cell 2011, 10:262-271.

13. Ayrinhac C, Margeot A, Ferreira NL, Chaabane FB, Monot F, Ravot G, Sonet $J-M$, Fourage L: Improved saccharification of wheat straw for biofuel production using an engineered secretome of Trichoderma reesei. Org Process Res Dev 2011, 15:275-278.

14. Jeoh T, Michener W, Himmel ME, Decker SR, Adney WS: Implications of cellobiohydrolase glycosylation for use in biomass conversion. Biotechnol Biofuels 2008, 1:1186-1198.

15. Liu T, Wang T, Li X, Liu X: Improved heterologous gene expression in Trichoderma reesei by cellobiohydrolase I gene (cbh1) promoter optimisation. ABBS 2008, 40:158-165.

16. Mathew GM, Sukumaran RK, Singhania RR, Pandey A: Progress in research on fungal cellulases for lignocelluloses degradation. J Sci Ind Res India 2008, 67:898-907.

17. Rahman Z, Shida Y, Furukawa T, Suzuki Y, Okada H, Ogasawara W, Morikawa Y: Application of Trichoderma reesei cellulase and xylanase promoters through homologous recombination for enhanced production of extracellular B-glucosidase I. Biosci Biotech Bioch 2009, 73:1083-1089.

18. Häkkinen M, Arvas M, Oja M, Aro N, Penttilä M, Saloheimo M, Pakula TM: Re-annotation of the CAZy genes of Trichoderma reesei and transcription in the presence of lignocellulosic substrates. Microb Cell Fact 2012, 11:134-160.

19. Klein-Marcuschamer D, Oleskowicz-Popiel P, Simmons BA, Blanch HW: The challenge of enzyme cost in the production of lignocellulosic biofuels. Biotechnol Bioeng 2012, 109:1083-1087.

20. Martinez D, Berka RM, Henrissat B, Saloheimo M, Arvas M, Baker SE, Chapman J, Chertkov O, Coutinho PM, Cullen D, Danchin EGJ, Grigoriev IV, Harris P, Jackson M, Kubicek C, Han CS, Ho I, Larrondo LF, Lopez de Leon A, Magnuson JK, Merino S, Misra M, Nelson B, Putnam N, Robbertse B, Salamov AA, Schmoll M, Terry A, Thayer N, Westerholm-Parvinen A, et al: Genome sequencing and analysis of the biomass-degrading fungus Trichoderma reesei (syn. Hypocrea jecorina). Nat Biotechnol 2008, 26:553-560.

21. Bloom JS, Khan Z, Kruglyak L, Singh M, Caudy AA: Measuring differential gene expression by short read sequencing: quantitative comparison to 2-channel expression microarrays. BMC Genomics 2009, 10:221-230.

22. Mortazavi A, Williams BA, McCue K, Schaeffer L, Wold B: Mapping and quantifying mammalian transcriptomes by RNA-seq. Nat Methods 2008, 5:621-628.

23. Wang $L$, Feng Z, Wang $X$, Wang $X$, Zhang $X$ : DEGseq: an $R$ package for identifying differentially expressed genes from RNA-seq data. Bioinformatics 2010, 26:136-138.

24. Cantarel BL, Coutinho PM, Rancurel C, Bernard T, Lombard V, Henrissat B: The Carbohydrate-Active EnZymes database (CAZy): an expert resource for Glycogenomics. Nucleic Acids Res 2009, 37:D233-D238.

25. Pel HJ, De Winde JH, Archer DB, Dyer PS, Hofmann G, Schaap PJ, Turner G, De Vries RP, Albang R, Albermann K, Andersen MR, Bendtsen JD, Benen JAE, Van den Berg M, Breestraat S, Caddick MX, Contreras R, Cornell M, Coutinho PM, Danchin EGJ, Debets AJM, Dekker P, Van Dijck PWM, Van Dijk A, Dijkhuizen L, Driessen AJM, D'Enfert C, Geysens S, Goosen C, Groot GSP, et al: Genome sequencing and analysis of the versatile cell factory Aspergillus niger CBS 513.88. Nat Biotechnol 2007, 25:221-231.

26. van den Brink J, de Vries RP: Fungal enzyme sets for plant polysaccharide degradation. Appl Microbiol Biotechnol 2011, 91:1477-1492. 
27. Quinlan RJ, Sweeney MD, Leggio LL, Otten H, Poulsen J-CN, Johansen KS, Krogh KBRM, Jørgensen Cl, Tovborg M, Anthonsen A, Tryfona T, Walter CP, Dupree P, Xu F, Davies GJ, Walton PH: Insights into the oxidative degradation of cellulose by a copper metalloenzyme that exploits biomass components. P Natl Acad Sci USA 2011, 108:15079-15084.

28. Harris PV, Welner D, McFarland KC, Re E, Poulson J-CN, Brown K, Salbo R, Ding H, Vlasenko E, Merino S, Xu F, Cherry J, Larsen S, Leggio LL: Stimulation of lignocellulosic biomass hydrolysis by proteins of glycoside hydrolase family 61: structure and function of a large, enigmatic family. Biochemistry 2010, 49:3305-3316.

29. Li X-L, Špániková S, de Vries RP, Biely P: Identification of genes encoding microbial glucuronoyl esterases. FEBS Lett 2007, 581:4029-4035.

30. Kester HC, Benen JAE, Visser J, Warren ME, Orlando R, Bergmann C, Magaud $D$, Anker D, Doutheau A: Tandem mass spectrometric analysis of Aspergillus niger pectin methylesterase: mode of action on fully methylesterified oligogalacturonates. Biochem J 2000, 346:469-474.

31. Mølgaard A, Kauppinen S, Larsen S: Rhamnogalacturonan acetylesterase elucidates the structure and function of a new family of hydrolases. Structure 2000, 8:373-383.

32. De Vries RP, Parenicova L, Hinz SWA, Kester HCM, Beldman G, Benen JAE, Visser J: The beta-1,4-endogalactanase A gene from Aspergillus niger is specifically induced on arabinose and galacturonic acid and plays an important role in the degradation of pectic hairy regions. Eur J Biochem 2002, 269:4985-4993.

33. Fujii T, Murakami K, Sawayama S: Cellulase hyperproducing mutants derived from the fungus Trichoderma reesei QM9414 produced large amounts of cellulases at the enzymatic and transcriptional levels. Biosci Biotechnol Biochem 2010, 74:419-422.

34. Ganzlin M, Rinas U: In-depth analysis of the Aspergillus niger glucoamylase $(g / a A)$ promoter performance using high-throughput screening and controlled bioreactor cultivation techniques.J Biotechnol 2008, 135:266-271.

35. Zhou Q, Zu J, Kou Y, Lv X, Zhang X, Zhao G, Zhang W, Chen G, Liu W: Differential involvement of $\beta$-glucosidases from Hypocrea jecorina in rapid induction of cellulase genes by cellulose and cellobiose. Eukaryot Cell 2012, 11:1371-1381.

36. Wang Z, Gerstein M, Snyder M: RNA-Seq: a revolutionary tool for transcriptomics. Nat Rev Genet 2009, 10:57-63.

37. Zhang J, Siika-aho M, Tenkanen M, Viikari L: The role of acetyl xylan esterase in the solubilisation of xylan and enzymatic hydrolysis of wheat straw and giant reed. Biotechnol Biofuels 2012, 4:60-69.

38. Saloheimo M, Paloheimo M, Hakola S, Pere J, Swanson B, Nyyssönen E, Bhatia A, Ward M, Penttilä M: Swollenin, a Trichoderma reesei protein with sequence similarity to the plant expansions, exhibits disruption activity on cellulosic materials. Eur J Biochem 2002, 269:4202-4211.

39. Foreman PK, Brown D, Dankmeyer L, Dean R, Diener S, Dunn-Coleman NS, Goedegebuur F, Houfek TD, England GJ, Kelley AS, Meerman HJ, Mitchell T, Mitchinson C, Olivares HA, Teunissen PJM, Yao J, Ward M: Transcriptional regulation of biomass-degrading enzymes in the filamentous fungus Trichoderma reesei. J Biol Chem 2003, 278:31988-31997.

40. Mao C, Obeid LM: Ceramidases: regulators of cellular responses mediated by ceramide, sphingosine and sphingosine-1-phosphate. Biochim Biophys Acta 2008, 1781:424-434.

41. Schmoll M, Zeilinger S, Mach RL, Kubicek CP: Cloning of genes expressed early during cellulase induction in Hypocrea jecorina by a rapid substraction hybridisation approach. Fungal Genet Biol 2004, 41:877-887.

42. Linder MB, Szilvay GR, Nakari-Setälä T, Penttilä M: Hydrophobins: the protein-amphiphiles of filamentous fungi. FEMS Microbiol Rev 2005 29:877-896

43. Ohtaki S, Maeda H, Takahashi T, Yamagata Y, Hasegawa F, Gomi K, Nakajima T, Abe K: Novel hydrophobic surface binding protein, $\mathrm{HsbA}$, produced by Aspergillus oryzae. Appl Environ Microb 2006, 72:2407-2413.

44. Rey M, Ohno S, Pintor-Toro JA, Llobell A, Benitez T: Unexpected homology between inducible cell wall protein QID74 of filamentous fungi and BR3 salivary protein of the insect Chironomus. Proc Natl Acad Sci U S A 1998, 95:6212-6216.

45. Dean RA, Talbot NJ, Ebbole DJ, Farman ML, Mitchell TK, Orbach MJ, Thon M, Kulkarni R, Xu J-R, Pan H, Read ND, Yong-Hwan L, Carbone I, Brown D, Oh YY, Donofrio N, Jeong JS, Soanes DM, Djonovic S, Kolomiets E, Rehmeyer C, Li W, Harding M, Kim S, Lebrun M-H, Bohnert H, Coughlan S, Butler J, Calvo S,
Ma L-J, et al: The genome sequence of the rice blast fungus Magnaporthe oryzae. Nature 2005, 434:980-986.

46. Wilson RA, Talbot NJ: Under pressure: investigating the biology of plant infection by Magnaporthe oryzae. Nat Rev 2009, 7:185-195.

47. Pao SS, Paulsen IT, Saier MH Jr: Major facilitator Superfamily. Microbiol Mol Biol $R$ 1998, 62:1-34.

48. Lingner U, Münch S, Deising HB, Sauer N: Hexose transporters of a hemibiotrophic plant pathogen: Functional variations and regulatory differences at different stages of infection. J Biol Chem 2011, 286:20913-20922.

49. Mach-Aigner A, Gudynaite-Savitch L, Mach RL: L-arabitol is the actual inducer of xylanase expression in Hypocrea jecorina (Trichoderma reesei). Appl Environ Microbiol 2011, 77:5988-5994.

50. Seiboth B, Pakdaman BS, Hartl L, Kubicek CP: Lactose metabolism in filamentous fungi: how to deal with an unknown substrate. Fungal Biol Rev 2007, 21:42-48.

51. Faghihi MA, Wahlestedt C: Regulatory roles of natural antisense transcripts. Nature Rev 2009, 10:637-643.

52. Dang $Y$, Yang $Q$, Xue Z, Liu Y: RNA interference in fungi: pathways, functions and applications. Eukaryot Cell 2011, 10:1148-1155.

53. Druzhinina IS, Schmoll M, Seiboth B, Kubicek CP: Global carbon utilisation profiles of wild-type, mutant, and transformant strains of Hypocrea jecorina. Appl Environ Microb 2006, 72:2126-2133.

54. Nakari-Setälä T, Paloheimo M, Kallio J, Vehmaanperä J, Penttilä M, Saloheimo M: Genetic modification of carbon catabolite repression in Trichoderma reesei for improved protein production. Appl Environ Microb 2009, 75:4853-4860.

55. Edgar R, Domrachev M, Lash AE: Gene Expression Omnibus: NCBI gene expression and hybridization array data repository. Nucleic Acids Res 2002, 30:207-210

doi:10.1186/1471-2164-14-541

Cite this article as: Ries et al:: Genome-wide transcriptional response of Trichoderma reesei to lignocellulose using RNA sequencing and comparison with Aspergillus niger. BMC Genomics 2013 14:541.

\section{Submit your next manuscript to BioMed Central and take full advantage of:}

- Convenient online submission

- Thorough peer review

- No space constraints or color figure charges

- Immediate publication on acceptance

- Inclusion in PubMed, CAS, Scopus and Google Scholar

- Research which is freely available for redistribution 